UCRL-JC-121439

PREPRINT

CONF $-950846 \cdots+3$

\title{
Reactive Flow Model Development for PBXW-126 Using Modern Nonlinear Optimization Methods
}

M. J. Murphy, R. L. Simpson, P. A. Urtiew, P. C. Souers, F. Garcia, and R. G. Garza

This paper was prepared for submittal to the 1995 American Physical Society Topical Conference

Seattle, WA

August 13-18, 1995

August 1995

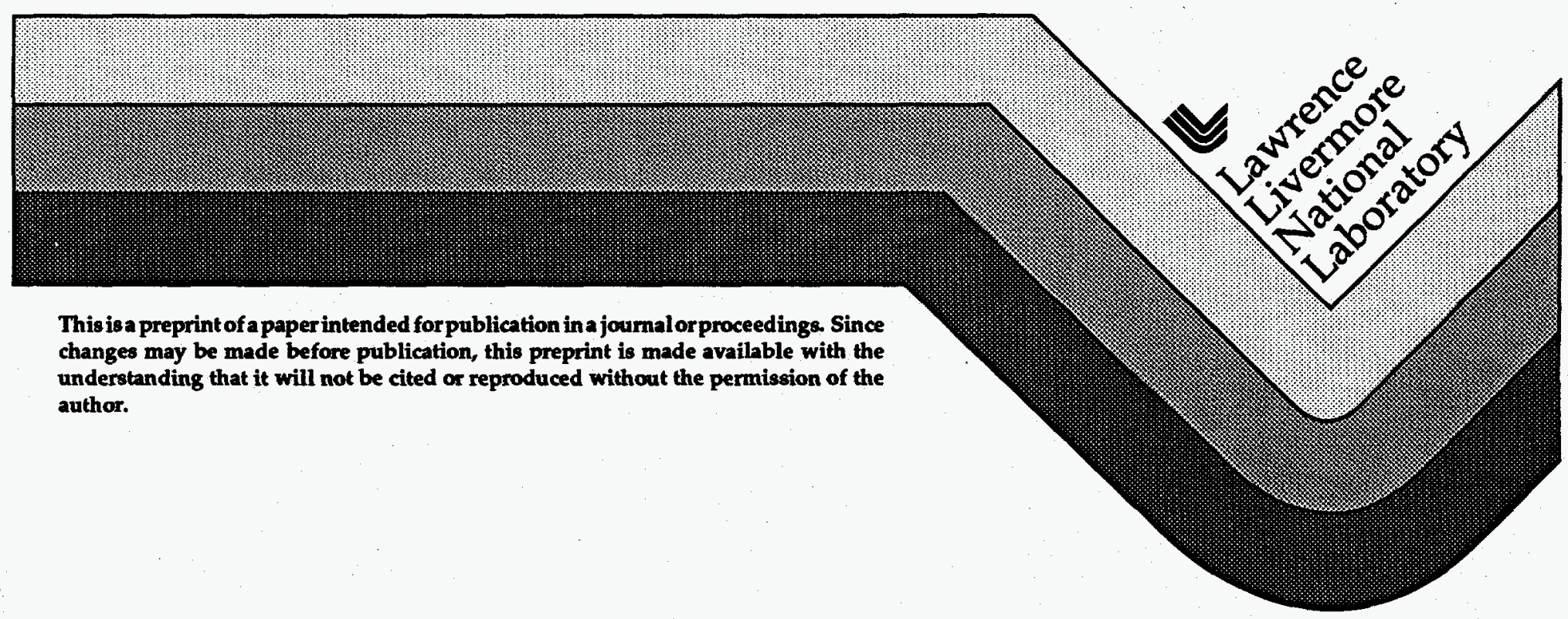




\section{DISCLAIMER}

This document was prepared as an account of work sponsored by an agency of the United States Government. Neither the United States Government nor the University of California nor any of their employees, makes any warranty, express or implied, or assumes any legal liability or responsibility for the accuracy, completeness, or usefulness of any information, apparatus, product, or process disclosed, or represents that its use would not infringe privately owned rights. Reference herein to any specific commercial product, process, or service by trade name, trademark, manufacturer, or otherwise, does not necessarily constitute or imply its endorsement, recommendation, or favoring by the United States Government or the University of California. The views and opinions of authors expressed herein do not necessarily state or reflect those of the United States Government or the University of California, and shall not be used for advertising or product endorsement purposes. 


\section{DISCLAIMER}

Portions of this document may be illegible in electronic image products. Images are produced from the best available original document. 


\title{
REACTIVE FLOW MODEL DEVELOPMENT FOR PBXW-126 USING MODERN NONLINEAR OPTIMIZATION METHODS
}

\author{
M.J. Murphy, R.L. Simpson, P.A. Urtiew, P.C. Souers, F. Garcia, R.G. Garza \\ Lawrence Livermore National Laboratory, PO Box 808, L-282, Livermore, CA 94550
}

\begin{abstract}
The initiation and detonation behavior of PBXW-126 has been characterized and is described. PBXW-126 is a composite explosive consisting of approximately equal amounts of RDX, AP, AL, and NTO with a polyurethane binder. The three term ignition and growth of reaction model parameters (ignition + two growth terms) have been found using nonlinear optimization methods to determine the "best" set of model parameters. The ignition term treats the initiation of up to $0.5 \%$ of the RDX. The first growth term in the model treats the RDX growth of reaction up to $20 \%$ reacted. The second growth term treats the subsequent growth of reaction of the remaining AP/AL/NTO. The unreacted equation of state (EOS) was determined from the wave profiles of embedded gauge tests while the JWL product EOS was determined from cylinder expansion test results. The nonlinear optimization code, NLQPEB/GLO, was used to determine the "best" set of coefficients for the three term Lee-Tarver ignition and growth of reaction model.
\end{abstract}

\section{INTRODUCTION}

The reactive flow parameters for simulating the initiation and detonation behavior of PBXW-126 were determined using the nonlinear optimization code NLQPEB/GLO. PBXW-126 is a composite high explosive (HE) consisting of approximately equal amounts of RDX, AP, AL, and NTO with a polyurethane binder. The three term form of the reactive flow model (ignition + two growth terms) was used to simulate the initiation response of this composite HE. The ignition term treats the initiation of up to $0.5 \%$ of the RDX. The first growth term treats the RDX growth of reaction up to $20 \%$. The second growth term treats the subsequent growth of reaction of the remaining AP/AL/NTO.

The unreacted EOS was determined from known $\mathrm{HE}$ properties and by matching simulations to a noreaction embedded gauge flyer impact experiment. The product EOS was determined from a JWL fit to a $100 \mathrm{~mm}$ cylinder test. The growth of reaction parameters were determined with NLQPEB/GLO by matching simulations to the experimental pressure traces from a shock to detonation transition (SDT) embedded gauge flyer impact experiment. The growth of reaction parameters were verified by comparing a $100 \mathrm{~mm}$ diameter wave front curvature simulation to experimental results.

\section{NONLINEAR OPTIMIZATION CODE}

The nonlinear optimization software package, NLQPEB/GLO $(1,2)$, consists of a controller, GLO (Global Local Optimizer), an optimization code NLQPEB (3), and the hydrocode, DYNA2D. GLO runs the optimization code and hydrocode in an iterative loop to minimize a figure of merit (FOM), the difference between the analysis and experimental results. NLQPEB uses a Broyden, Fletcher Goldfarb, \& Shanno variable metric sequential quadric programming methodology with a modified Powell merit function $(4,5)$. It treats DYNA2D as a function, supplying material property parameters. DYNA2D returns the FOM, which is the squared error difference between the experimental result and the calculated result. GLO runs NLQPEB and DYNA2D in a loop until it finds the "best" set of material parameters by minimizing the FOM.

\section{PBXW-126 PROPERTIES}

PBXW-126 is a composite explosive consisting of $20 \mathrm{wt} \% \mathrm{RDX}, 20 \% \mathrm{AP}, 26 \% \mathrm{Al}, 22 \% \mathrm{NTO}$, and $12 \%$ polyurethane. The density is $1.80 \mathrm{~g} / \mathrm{cc}$, with a detonation velocity of $0.647 \mathrm{~cm} / \mu \mathrm{sec}$ and Us-Up of $0.222 \mathrm{~cm} / \mu \mathrm{sec}+2.0 \mathrm{Up}$. Small scale safety data is summarized in Table 1 . 
TABLE 1. Small Scale Safety Data for PBXW-126

\begin{tabular}{|c|c|c|c|}
\hline & PBXW126 & TNT & HMX \\
\hline Impact $^{\mathrm{a}}$ & 95.7 & 148 & 32 \\
\hline CRT $^{\mathrm{b}}$ & 0.033 & $\leq 0.012$ & $\leq 0.025$ \\
\hline DSC $^{\mathrm{C}}$ & 196 & 250 & 270 \\
\hline Spark $^{\mathrm{d}}$ & no rxn & no rxn & no rxn \\
\hline Friction $^{\mathrm{e}}$ & 4.0 & 11.6 & 11.6 \\
\hline
\end{tabular}

a Impact (cm) $-2.5 \mathrm{~kg}$, Type $12 \mathrm{~A}, 35 \mathrm{mg}$ pressed pellets.

b Chemical reactivity test. $120^{\circ} \mathrm{C}$ for $22 \mathrm{~h}$ at $1 \mathrm{~atm} \mathrm{Hg}$.

c Differential scanning calorimeter $\left({ }^{\circ} \mathrm{C}\right)-10^{\circ} \mathrm{C} / \mathrm{min}$,

max of endothermic response \& onset of exotherm.

d $1 \mathrm{~J}$ with $510 \mathrm{~W}$.

e Friction (kg), BAM.

\section{Reactants Equation of State}

The JWL EOS of the reactants (unreacted material) was determined from an embedded gauge nonreactive flyer plate impact experiment. The test setup is shown in Figure 1. An impact velocity of $0.94 \mathrm{~mm} / \mu \mathrm{sec}$ produced no reaction in the HE. Shock wave times of arrival at the gauges were used to determine the reactants EOS given in Table 2. A comparison of the calculated and experimental shock wave profiles is shown in Figure 2.

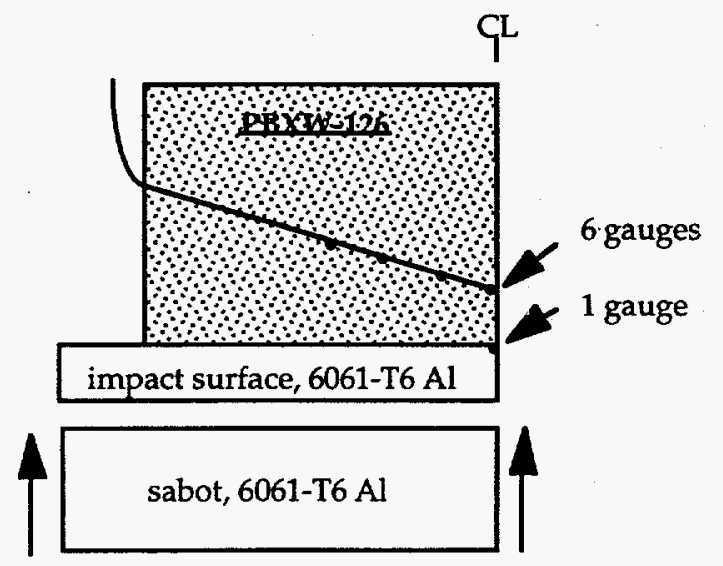

FIGURE 1. Embedded gauge test setup.

TABLE 2. JWL Reactants EOS parameters

\begin{tabular}{|c|c|c|c|}
\hline $\mathrm{A}$ (mbar) & $3.1696 \mathrm{e}+02$ & $\rho(\mathrm{g} / \mathrm{cc})$ & 1.800 \\
\hline $\mathrm{B}$ (mbar) & $-2.596 \mathrm{e}-03$ & $\mathrm{CV}(\mathrm{mbar} / \mathrm{K})$ & $2.487 \mathrm{e}-05$ \\
\hline $\mathrm{R}_{1}$ & 0.947 & $\left.\mathrm{~T}_{0}{ }^{0} \mathrm{C}\right)$ & 298.0 \\
\hline $\mathrm{R}_{2}$ & -1.559 & $\mathrm{E}_{0}(\mathrm{mbar} \mathrm{cc} / \mathrm{cc})$ & $6.759 \mathrm{e}-03$ \\
\hline$\omega$ & 0.912 & & \\
\hline
\end{tabular}

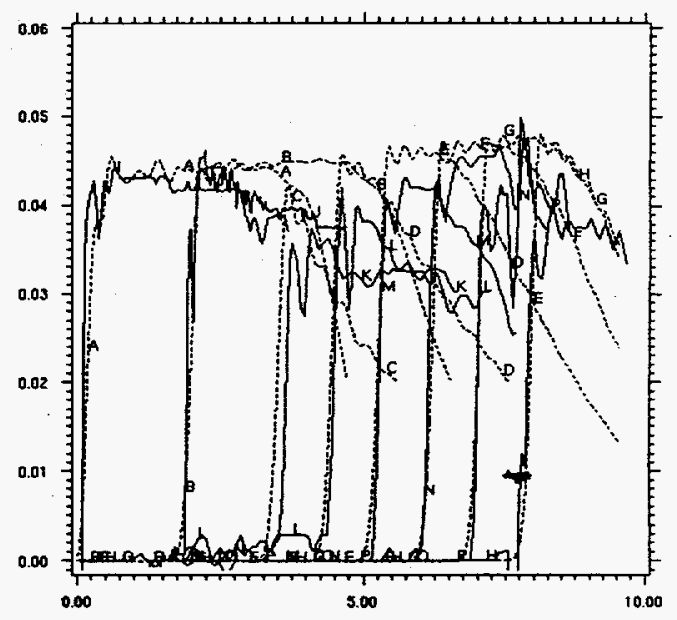

FIGURE 2. Comparison of calculated and experimental wave profiles for the $0.94 \mathrm{~mm} / \mu \mathrm{sec}$ non-reactive test.

\section{Products Equation of State}

The JWL EOS of the detonation products was determined from a fit to a $100 \mathrm{~mm}$ diameter, full wall, copper cylinder test. The JWL products EOS parameters are given in Table 3. Small and large volume cylinder wall velocity vs. expansion histories are shown in Figures 3 \& 4.

TABLE 3. JWL Products EOS parameters

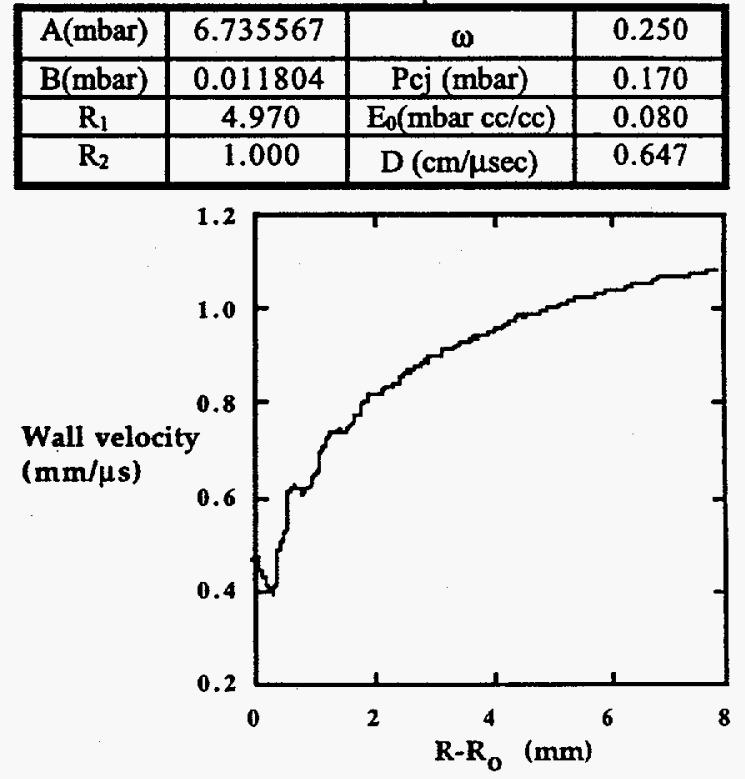

FIGURE 3. Cylinder wall velocity $(\mathrm{mm} / \mu \mathrm{sec})$ versus cylinder wall radius expansion, $\mathrm{R}_{-} \mathrm{R}_{0}(\mathrm{~mm})$. 


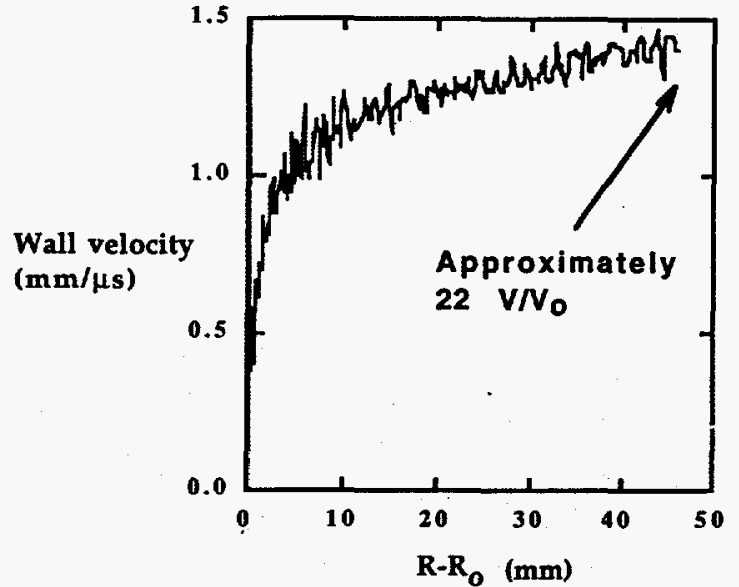

FIGURE 4. Cylinder wall velocity (mm/ $\mathrm{msec}$ ) versus cylinder wall radius expansion, $\mathrm{R}-\mathrm{R}_{0}(\mathrm{~mm})$.

\section{REACTIVE FLOW EOS}

The three term form of the reactive flow model (ignition + two growth terms) was used to simulate the initiation response of this composite explosive. The reaction rate for this form of the model is given in the Equation 1. The ignition term treats the initiation of up to $0.5 \%$ of the RDX. The first growth term in the model treats the RDX growth of reaction up to $20 \%$ reacted. The second growth term treats the subsequent growth of reaction of the remaining $\mathrm{AP} / \mathrm{AL} / \mathrm{NTO}$ mixture.

$$
\begin{aligned}
& d F / d t= \\
& I \cdot(1-F)^{b}\left(\rho / \rho_{0}-1-a\right)^{x}+G_{1}(1-F)^{c} F^{d} p^{y}+G_{2}(1-F)^{0} F^{g} p^{z}
\end{aligned}
$$

\section{Model Parameter Determination}

The NLQPEB/GLO optimization code was used to determine eight of the parameters used in the reaction rate equation. The other seven parameters were held constant at values defined for typical $\mathrm{RDX} / \mathrm{HMX}$ based explosives. The eight parameters determined by the optimization code specify the growth of reaction terms and growth rate form factors. A summary of all of the values is given in Table 4. A plot of the growth rate form factor given by Equation 2 is shown in Figure 5 for $\mathrm{c}=$ 0.9 and $0.0<\mathrm{d}<1.0$.

$$
\text { growth rate form factor }=G \cdot(1-F)^{c} \cdot F^{d}
$$

TABLE 4. Ignition and growth of reaction parameters

\begin{tabular}{|c|c|c|c|}
\hline ignition & $\mathrm{I}$ & fixed & 40.0 \\
\hline & $\mathrm{b}$ & fixed & 0.667 \\
\hline & $\mathrm{a}$ & fixed & 0.01 \\
\hline & $\mathrm{x}$ & fixed & 4.0 \\
\hline growth 1 & $\mathrm{G}_{1}$ & variable & 124.0 \\
\hline & $\mathrm{c}$ & variable & 0.900 \\
\hline & $\mathrm{d}$ & variable & 0.100 \\
\hline & $\mathrm{y}$ & fixed & 3.0 \\
\hline growth 2 & $\mathrm{G}_{2}$ & variable & 41.0 \\
\hline & $\mathrm{e}$ & variable & 0.900 \\
\hline & $\mathrm{g}$ & variable & 0.200 \\
\hline & $\mathrm{z}$ & fixed & 2.0 \\
\hline ignition $\max$ & $\mathrm{f}_{\mathrm{ig}} \mathrm{mx}$ & variable & 0.005 \\
\hline grow 1 max & $\mathrm{f}_{\mathrm{g} 1 \mathrm{mx}}$ & fixed & 0.200 \\
\hline grow 2 min & $\mathrm{f}_{\mathrm{g} 2 \mathrm{mn}}$ & variable & 0.035 \\
\hline
\end{tabular}

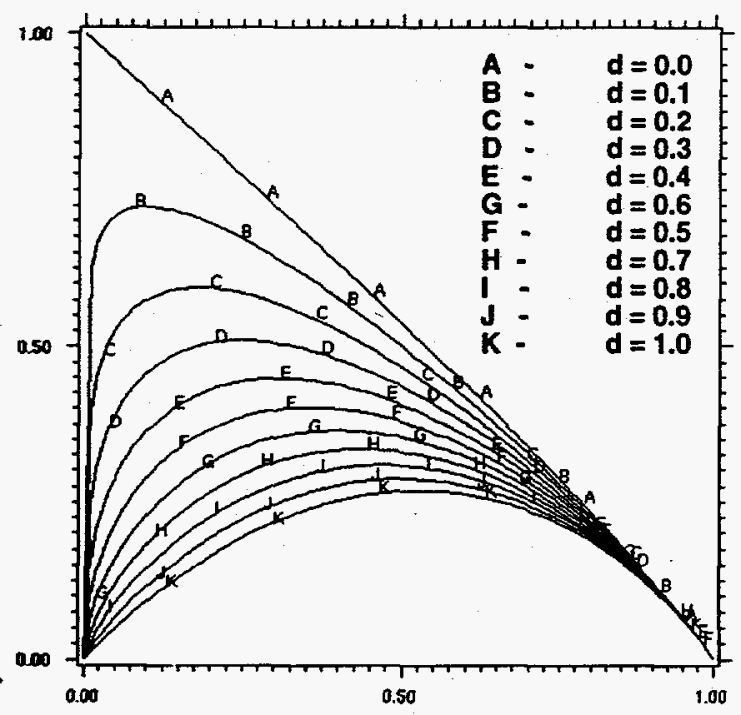

FIGURE 5. Growth rate form factor as a function of $F$ (fraction reacted) for $G=1.0, c=0.9$, and $0.0<d<1.0$.

\section{SDT Simulation}

A comparison of the calculated and experimental shock wave profiles for the $1.409 \mathrm{~mm} / \mu \mathrm{sec}$ embedded gauge SDT impact experiment is shown in Figure 6. This DYNA2D SDT simulation was iterated by the NLQPEB/GLO code until a match to the experimental results was obtained. The figure of merit was based on the detonation wave arrival times at the gauges and the magnitude of the growth of the reaction observed by the gauges. 


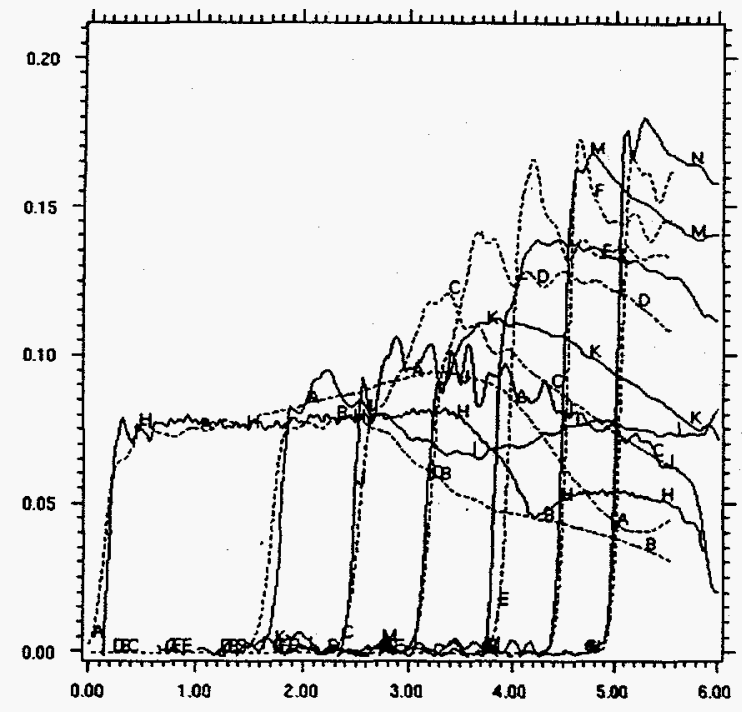

FIGURE 6. Comparison of calculated and experimental wave profiles for the $1.409 \mathrm{~mm} / \mu \mathrm{sec}$ SDT test.

\section{DETONATION WAVE CURVATURE}

The results of a $100 \mathrm{~mm}$ diameter detonation wave front curvature experiment (breakout) were used to verify the ignition and growth of reaction parameters determined by NLQPEB/GLO. The experimental results are shown in Figure 7 . The DYNA2D calculated results are shown in Figure 8.

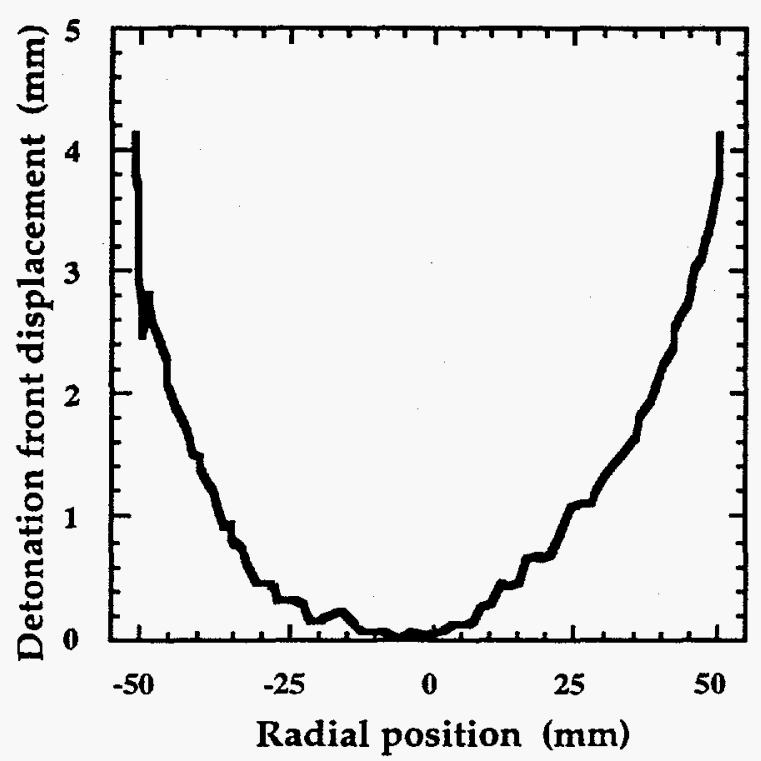

FIGURE 7. Experimental wave front curvature results.

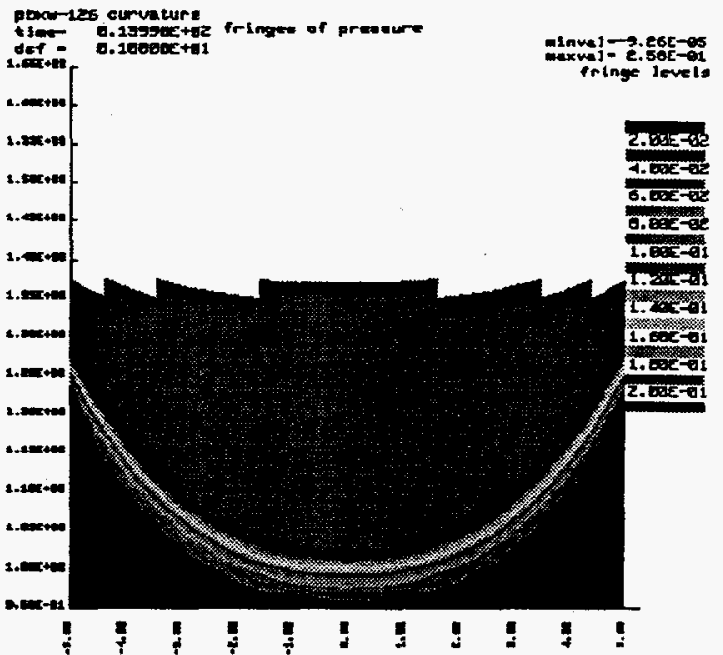

FIGURE 8. Results of the DYNA2D calculated 4 inch diameter wave front curvature simulation.

\section{CONCLUSIONS}

The modern nonlinear optimization code package NLQPEB/GLO is fast, accurate, and very useful for parameterizing the ignition and growth of reaction model. It is important to note that the hydrocode model must be robust and treat the salient features of the growth of the explosive reaction. The accuracy of the "optimized" set of reaction rate parameters is primarily limited by the accuracy of the hydrocode numerical solution (not the optimization code).

This work was funded by Dr. R. Bowen, U.S.Navy.

\section{REFERENCES}

I. M.J. Murphy and E.L. Baker, "Using nonlinear optimization methods to reverse engineer liner material properties from EFP tests", 15th Int. Symp. on Ballistics, Jerusalem, Israel, (1995).

2. E.L. Baker \& M.J. Murphy, "An application of variable metric nonlinear optimization to two-dimensional LaGrangian EFP geometry modeling", 15th Int. Symp on Ballistics, Israel, (1995). 3. E.L. Baker, "Modeling and optimization of shaped charge liner collapse and jet formation", ARAED-TR-92019, (1993).

4. P.E. Gill, W. Murray, \& M.H. Wright, Practical Optimizution, Academic Press, ISBN 0-12-283950-1, (1981).

5. M.J.D. Powell, "A fast algorithm for nonlinearly constrained optimization calculations", Biennial Conference, Dundee 1977.

This work was performed under the auspices of the U.S. Dept. of Energy by Lawrence Livermore National Laboratory under contract No. W-7405-ENG-48. 